Como citar este artículo en APA: Urrego-Romero, J. E. (2019). Estilo de vida carismático en el catolicismo: Proximidades sociológicas a las creencias y prácticas de la Renovación Carismática Católica. Cuestiones Teológicas, 46 (106), 379-412.

doi: http://doi.org/10.18566/cueteo.v46n106.a08

Fecha de recepción: 10 de julio de 2019

Fecha de aceptación: 29 de octubre de 2019

\title{
ESTILO DE VIDA CARISMÁTICO EN EL CATOLICISMO: PROXIMIDADES SOCIOLÓGICAS A LAS CREENCIAS Y PRÁCTICAS DE LA RENOVACIÓN CARISMÁTICA CATÓLICA ${ }^{1}$
}

\author{
Charismatic Lifestyle within Catholicism: Sociological Approach to Beliefs \\ and Practices of Catholic Charismatic Renewal
}

Estilo de vida carismático no catolicismo: proximidades sociológicas às crenças e práticas de renovação carismática católica

John Edisson Urrego-Romero²

1 Este artículo es parte del resultado de la investigación para optar por el título de Maestría en Sociología denominada "La Renovación Carismática Católica en Colombia: Origen y desarrollo" realizada en la Universidad Nacional de Colombia en Bogotá. En la tesis se realizó una reconstrucción sociológica de este movimiento religioso en Colombia.

2 Magíster en Sociología por la Universidad Nacional de Colombia. Licenciado en Filosofía (2012) de la Universidad Santo Tomás. Teólogo de la Universidad Pontificia Bolivariana (2009). Actualmente docente de la Universidad Central (Colombia). Correo electrónico: jeurregor@unal.edu.co; jurregor@ucentral.edu.co 


\section{Resumen}

El presente artículo tiene como objetivo aproximarse a las prácticas y creencias del creyente carismático perteneciente a la Renovación Carismática Católica desde una perspectiva sociológica. En primer lugar, se propone una revisión teórica sociológica y antropológica de este sistema religioso, cuya conceptualización permite observar particularidades en los procesos de adaptación de estas creencias y prácticas pentecostales a la vivencia religiosa de un sector particular del catolicismo, y luego se enmarca su incidencia en los procesos de habituación y configuración de un estilo de vida carismático dentro del catolicismo. La metodología consistió en una revisión documental y entrevistas a líderes carismáticos de Cali y Bogotá. Se reconoce una evolución de este sistema de creencias y prácticas cuya proximidad teórica evidencia una progresiva configuración de estilo de vida propio del creyente carismático católico dentro de la institucionalidad eclesiástica en dos sentidos. Primero, un estilo habituado en comunidades de creyentes diferenciadas por su especialización carismática dentro de la Iglesia Católica cuya evolución condujo a constituirse en organizaciones religiosas dentro de la institución; segundo, una progresiva incorporación de prácticas y creencias carismáticas en la liturgia católica de las parroquias en Colombia.

Palabras clave: Renovación Carismática Católica; Creencias y prácticas carismáticas; Organización religiosa; Sociología de la religión.

\section{Abstract}

The article examines, from a sociological perspective, the practices and beliefs of the charismatic believer belonging to Catholic Charismatic Renewal. First, a sociological and anthropological theorical review of this religious system is undertaken, which makes it possible to appreciate the peculiarities of the adaptation processes of these pentecostal beliefs and practices within a specific segment of Catholicism and to frame its impact on the processes of habituation and establishment of charismatic lifestyle within Catholicism. Methodologically, it is based on documentary research, interviews with charismatic leaders and believers, and participant observation in charismatic communities located 
in Cali, Bogota and Boyaca. Thus, an evolution of this system of beliefs and practices is recognized, which reveals a progressive establishment of a lifestyle of the charismatic believer within the ecclesiastic institution in, at least, two ways: first, a familiar style in communities that are different because of their charismatic specialization within Catholic Church and whose evolution led to the establishment of religions organizations within the institution; second, a progressive inclusion of charismatic beliefs and practices within catholic liturgy in Colombian parishes.

Key Words: Catholic Charismatic Renewal; Charismatic Beliefs and Practices; Religious Organization; Sociology of Religion.

\section{Resumo}

Esse artigo tem por objetivo a abordagem das práticas e crenças do fiel carismático pertencente à renovação carismática católica desde uma perspectiva sociológica. Em primeiro lugar, propóe-se uma revisão teórica sociológica e antropológica desse sistema religioso cuja conceituaçáo permite observar particularidades nos processos de adaptação dessas crenças e práticas pentecostais à vivência religiosa de um setor particular do catolicismo para depois estabelecer sua incidência nos processos de habituação e configuração de um estilo de vida carismático dentro do catolicismo. A metodologia consistiu em uma revisão documental, entrevistas a lideranças carismáticas e fieis, da mesma forma observações participante em comunidades carismáticas de Cali, Bogotá e Boyacá. Reconhece-se uma evolução desse sistema de crenças e práticas cuja abordagem empírica evidencia uma progressiva configuração de estilo de vida próprio do fiel carismático católico dentro da institucionalidade eclesiástica em dois sentidos: Primeiro, um estilo frequente nas comunidades de fieis caraterizados por sua especialização carismática dentro da igreja católica, cuja evolução ocasionou sua constituição como organizaçóes religiosas dentro da instituição. Segundo, uma progressiva incorporação de práticas e crenças carismáticas na liturgia católica das paróquias em Colômbia.

Palavras Chave: Renovação Carismática Católica; crenças e práticas carismáticas; organização religiosa; sociologia da religião. 


\section{Introducción}

El protagonismo laical dentro del catolicismo aparece explícitamente y con centralidad en las reflexiones del Concilio Vaticano II. Sin embargo, sus posturas progresistas generaron fuerzas y divergencias en el interior de la Iglesia Católica debido a su contraste con la tradición dominante del catolicismo dado hasta Pío $\mathrm{XII}^{3}$. El resultado de estas tensiones fue la constitución de movimientos de resistencia a nivel religioso y secular que propendieron por repensar el papel del cristiano en la sociedad a través de un activismo social y político, así como por brindar solución a problemáticas emergentes en un entorno convulsionado por la posguerra y sus consecuencias socioeconómicas.

La ruptura de estos movimientos con la tradición permeó todas las esferas sociales, incluida la religiosa. Los católicos, muchos jóvenes laicos, religiosos y sacerdotes, se unieron a las causas sociales, cambiando su modo de autopercibirse y organizarse como comunidad creyente. Se crearon nuevos espacios de libertad social y se configuraron nuevas experiencias de "ser creyente y estar en la Iglesia", luego reconocidas en el tiempo y legitimadas por la autoridad eclesiástica a través de la institucionalización de movimientos eclesiales cuyas distinciones y particularidades correspondían a los intereses o el carisma del fundador.

Uno de estos movimientos fue la Renovación Carismática Católica (RCC), cuyo origen se dio en un ambiente de diálogo ecuménico en Estados Unidos (1967) pero con un auge relevante en América Latina y posteriormente en Europa durante los años 70 . La situación anómica de una sociedad en progresiva industrialización y urbanización con altos índices de pobreza, fue no solo el contexto propicio para la aparición de la clase media, sino la circunstancia social que favoreció el crecimiento de este movimiento en las clases pobres (Bergunder, 2009).

3 La concepción de una Iglesia inmovilizada y envejecida (desde la misa en latín hasta la inferioridad de los laicos con relación al clero) será una nota característica hasta el pontificado de Pio XII, convirtiéndose en el escenario propicio para la renovación de la Iglesia y de la vida cristiana (Alberigo, 2005). 
En este sentido, Arias (2003) afirma que en América Latina el impacto de los principios del Concilio Vaticano II al lado de la encíclica Populorum Progressio de Pablo VI (1967) y la Conferencia Episcopal Latinoamericana de Medellín (1968) propiciaron reflexiones que le permitieron a la jerarquía desarrollar nuevas formas de responder a las necesidades sociales en "los países empobrecidos" a partir de la innovación teológica y la constitución de organizaciones sacerdotales y laicales novedosas que trabajaran socialmente por las comunidades menos favorecidas.

Este entorno conciliar fue el nuevo espacio para la participación laical dentro de la Iglesia latinoamericana que animó tanto la autonomía del laico en el orden temporal como su acceso a la administración de carismas para ejercer ministerios dentro de la Iglesia (antes exclusivos para los sacerdotes), convirtiéndose en un campo donde emergió una novedosa diversidad en la Iglesia católica denominada Nuevos Movimientos Religiosos ${ }^{5}$ (NMR) en medio de una pretendida imagen de homogeneidad (Suárez, 2014). En este marco, la RCC se puede identificar como un movimiento que oscila entre una Iglesia tradicional y lo nuevo o renovador del pentecostalismo por su afinidad social, especialmente en comunidades marginales. Según Holland (2011), tal ambigüedad de la RCC es lo que ha determinado que la inclusión

4 Esta categoría fue asumida por la corriente de la teología de la liberación en la que se consideraba que las condiciones sociales de los pueblos latinoamericanos fueron causadas por la estructura de un Estado favorable a un capitalismo imperante y una explotación de los más pobres en el campo y los cinturones de miseria en las ciudades latinoamericanas (Oliveros Maqueo, 1990).

5 Sobre la categoría de Nuevo Movimiento Religioso se presenta la problemática de que no existe un consenso en su delimitación. Por lo general, se hace uso del término para referirse a cualquier grupo sea tanto "de origen reciente" como "diferente de las religiones existentes". En ocasiones grupos religiosos cristianos, (evangélicos, por ejemplo), grupos que rebasan el dogma cristiano (los mormones, los adventistas) o no cristianos (grupos amerindios, africanos, orientales) han sido estudiados o clasificados como NMR. Sin embargo, tanto la Iglesia católica, la Iglesia ortodoxa, como las iglesias evangélicas, catalogan a estos grupos con el concepto peyorativo «secta», debido a las divergencias teológicas según su ortodoxia cristiana. Por tanto, el uso de la categoría NMR referido a la RCC en esta investigación se asumió análogamente a la categoría de organización religiosa católica o movimiento eclesial. 
en diferentes partes del mundo haya tenido enfoques y resultados distintos a nivel regional, nacional e internacional.

Para el caso de América Latina, los estudios alrededor de la RCC han planteado posturas en ocasiones divergentes. Una postura sostiene que la RCC es un movimiento de continuidad con el catolicismo popular ${ }^{6}$ que incorpora creencias mágicas y prácticas emotivas o no racionales (Bastian, 1994, 1997; Csordas, 1990) como respuesta política al incremento acelerado de las sectas y la necesidad de una recatolización (Bastian, 1997; Bergunder, 2009; Carranza, 2008; De Roux, 2017; Stoll, 1985).

Sin embargo, otros investigadores consideran que la RCC no necesariamente corresponden a un catolicismo popular sino que obedece a una nueva forma de religiosidad que termina por configurar una práctica religiosa espiritualista (Soneira, 1996), con una estructura horizontal y vertical a nivel organizativo (Cabrera, 2001; De la Torre, 2006) que posibilita la formación de una diversidad de identidades religiosas en el interior de la Iglesia católica (De la Torre, 2001, 2006, 2007; Giménez Béliveau, 2008) y que ejerce un control a través de los medios masivos de comunicación (Carranza, 2005, 2011; Viotti, 2011).

En el caso de Colombia, los estudios adelantados por la investigadora Angélica Ospina ilustran estas mismas dinámicas donde los motivos imbricados en valores éticos, morales, estéticos y socioculturales hacen parte del atractivo del movimiento como "una alternativa identitaria y de sanación para sus adeptos” (Ospina Martínez, 2006, p. 248) donde las expresiones de la feligresía se incorporan en lo emocional, lo comunitario, lo demoniaco, lo juvenil que cobran relevancia en la reestructuración del campo religioso dentro de la Iglesia católica en el país (Ospina Martínez, 2004, 2006, 2007).

6 De acuerdo con Frigerio (1998) el catolicismo popular se asocia al culto prácticamente paralelo e independiente de la Iglesia y del control clerical en el que la feligresía no sólo espera resultados mágicos, sino que media su relación con la divinidad a través de imágenes, la Virgen, santos o los muertos en vez de (o paralelamente con) una mediación de la Iglesia a través de la disciplina sacramental. 
En este sentido, la comprensión del movimiento de RCC como una continuidad de catolicismo popular durante el período próximo al origen de la RCC en los años 70 no es necesariamente general en el continente, ya que algunas experiencias de este movimiento fueron una respuesta a las ideas sociales y liberacionistas en América Latina como se evidenció en el caso particular de Colombia a través de la parroquia San Juan Bautista de Cali donde se adaptaron prácticas de la RCC con posturas de la Teología de la Liberación (Entrevista a Weigand, 2018) ${ }^{7}$. Si bien la distinción corresponde a casos particulares, esto demuestra la diversidad de trayectorias que pudo tener este movimiento carismático en diferentes partes del continente.

Por otro lado, durante el período de consolidación de la RCC en los 80 y 90, se evidencia la vuelta hacia una religiosidad más enmarcada en la tradición y un catolicismo integrista, situación que es afín a la tesis de Bastian (1997) donde afirma que la diferencia entre catolicismo y pentecostalismo es cada vez más incipiente $\mathrm{Al}$ respecto, este período se caracteriza por un entorno de mercado religioso donde la adaptación se convierte en una forma de entrar en competencia y donde la distinción se establece más a nivel organizacional que a nivel del sistema de creencias y prácticas.

En la actualidad, el movimiento de la RCC se observa como un pluralismo religioso resultante de este proceso de convulsión eclesiástica e innovación organizacional del laicado en América Latina, que se vio revestido de una nueva legitimidad en el discurso de los principales jerarcas de la Iglesia latinoamericana en contra de las posturas liberacionistas y progresistas, especialmente del Celam Medellín, y que se enraizaron posteriormente en una vuelta al conservadurismo durante el período de Juan Pablo II, pero con una nueva adaptación al mundo secular. En esta línea, es ilustrativo y protagónico el caso del cardenal Alfonso López Trujillo ${ }^{8}$ en

7 Monseñor William Weigand conocido como el Padre Guillermo fue uno de los protagonistas dentro de la RCC en Colombia. Fue el sacerdote americano que introdujo la RCC en la Parroquia de San Juan Bautista de Cali a finales de los años 60's. Para profundizar en la historia de este líder carismático ver "La Renovación Carismática Católica en Colombia: Origen y desarrollo” realizada por el autor en la Universidad Nacional de Colombia en Bogotá.

8 El polémico obispo colombiano Alfonso López Trujillo es quien desde la presidencia 
Colombia y América Latina cuando ejerció presiones durante su liderazgo como presidente del CELAM (Arias, 2003; Echeverry Pérez, 2007; Salazar Palacio, 1996).

Desde esta perspectiva, se puede evidenciar entonces un desplazamiento -sociológico y pastoral- de las diferentes comunidades religiosas en el campo religioso católico que se pueden ubicar dos puntos: el "centro" y la "periferia" dependiendo de la clase social a la que pertenecían. En "centro" se ubicaron todos aquellos miembros de la jerarquía o de clases sociales urbanas y simpatizantes con la tradición religiosa que se afiliaron a la institucionalidad con grupos que reivindicaban la continuidad del catolicismo clásico9 ${ }^{9}$ Por otro lado, los sectores que se ubicaron en la "periferia" fueron aquellos grupos emergentes que pertenecían casi siempre a la clase media y los sectores populares al ser propicios para las misiones, atención de nuevas diócesis, organización de comunidades de base que articulaban sus prácticas y creencias religiosas a motivos sociales y políticos (Soneira, 1996).

Si bien las reflexiones conciliares jugaron un papel fundamental para legitimar la participación laical dentro de la Iglesia, fue la exhortación apostólica de Juan Pablo II (1988) Christifidelis Laici la que confirmó e impulsó la acción de los laicos por medio de grupos apostólicos que expresaban su experiencia al interior de la Iglesia desde una renovada dimensión carismática. La jerarquía reconoció dicha actividad como parte constitutiva de la esencia institucional y que se afirma en la conformación de los movimientos eclesiales y las nuevas comunidades en el interior

del CELAM reivindicó una tendencia de clausura y neoconservadurismo de la Iglesia como la estrategia para responder a "la nueva evangelización" en América Latina, una política de propagandismo católico para recuperar el pretendido monopolio católico. Sin embargo, las resistencias internas y la emergencia de los NMR permiten a hacer lecturas más complejas de cómo estos movimientos, al contrario de la pretensión jerárquica, posibilitaron el incremento de pluralización y desregularización dentro del catolicismo.

9 La tradición del catolicismo constituyó movimientos integristas como el Opus Dei, el movimiento de Marcel Lefebvre, incluso el movimiento neocatecumenal fundado por el laico espańol Kiko Argüello que operan dentro del catolicismo resignificando las tradiciones doctrinales en obediencia al orden jerárquico de la Iglesia católica. 
de la Iglesia de acuerdo con el atractivo que el fundador ejerce sobre los participantes de la experiencia espiritual (Soneira, 2005).

De este modo, los movimientos eclesiales reconocidos oficialmente por la autoridad eclesiástica se presentan como formas de autorrealización y reflejos de la unidad eclesial para suplir interrogantes, malestares y tensiones suscitados en el interior de la Iglesia, siendo la jerarquía o especialistas sacerdotales quienes disciernen y garantizan la autenticidad del carisma. No obstante, la jerarquía no tuvo gran éxito en tal control pues muchas de estas comunidades crecieron y se desarrollaron especialmente en sectores medios y populares de las ciudades latinoamericanas donde tuvieron un rápido crecimiento en los años 90, afianzando un individualismo de tipo "ético o religioso" (Suárez, 2014)

Por ello, la RCC corresponde a un movimiento carismático cuyas afinidades se enmarcan en una pluralidad de formas en el cristianismo latinoamericano que se caracterizan por la festividad, el sincretismo litúrgico y doctrinal, el comunitarismo y la opción social, dándose una continuidad entre el catolicismo tradicional, comunidades evangélicas y el pentecostalismo propio de las comunidades emocionales (Irarrázaval, 2000). Según De la Torre (2007), estos rasgos de cristianismo emotivo en el catolicismo muestran una profunda transformación en el interior de la institución "para adaptarse a los ritmos y cambios del mundo secularizado, lo que incide en la formación de una diversidad de subidentidades religiosas al interior de la Iglesia católica” (p. 12).

\section{Sistema de creencias de la RCC}

La principal creencia en la RCC que diferencia al creyente carismático del creyente católico tradicional es la renovación a través del bautismo en Espíritu Santo ${ }^{10}$. El mensaje fundamental de la RCC se puede sintetizar

10 La experiencia del bautismo en el Espíritu Santo se retoma de los pasajes bíblicos de Mt 3, 11 en referencia al suceso de San Juan Bautista cuando anuncia el bautizo 
en "El Espíritu Santo renueva la fe del creyente a través de su espíritu" (ICCE, 1977). Desde una perspectiva teológica cristiana, la dimensión carismática de la Iglesia católica se asocia doctrinalmente al Espíritu Santo, cuya función religiosa, según se expresa en el catecismo católico, es la de "renovar" constantemente a la Iglesia por medio de sus dones o carismas ${ }^{11}$.

La categoría renovación dentro del catolicismo se comprende como una forma de volver a las fuentes para experimentar el Pentecostés, aquel acontecimiento en el que se simboliza la posesión espiritual divina representada en lenguas de fuego y manifestaciones de glosolalia por parte de los iniciados en el cristianismo. Este suceso fue no solo el fundamento del Concilio Vaticano II sino el sentido de la RCC que le posibilitó afianzar el sistema de creencias católico a partir de una experiencia personal más cercana a la emoción, los sentimientos y los sentidos que a menudo se vuelven intensos y extraordinarios (Cabrera, 2001; Csordas, 1990; MacArthur, 1994). Al respecto, el padre Diego Jaramillo ${ }^{12}$ afirmó que la renovación permitió "compartir las experiencias de fe y continuar avivando el fuego del Espíritu en comunidad como en los Hechos de los apóstoles" (Entrevista Jaramillo, 2017)

como la posibilidad de conversión a través de la confesión de los pecados y Hch1, 5 donde se afirma que "Juan bautizó con agua, pero vosotros seréis bautizados en el Espíritu Santo dentro de pocos días»" (Tomado de la Biblia de Jerusalén).

11 Desde la teología, se comprenden como "manifestación sensible y perceptible de la acción del Espíritu Santo" (Fernández, 1978); como "don de servicio”, una gracia concedida al individuo y al servicio de la comunidad (Grasso, 1984); y en el sentido de la RCC (O'Connor, 1973) lo circunscribe en 4 sentidos: un hecho extraordinario (milagros y curaciones), un hecho extraordinario que sin ser sacramental puede ser un don (profecía), una gracia dada a alguien en vistas al bien común (catequesis, sacerdocio) y cualquier gracia (suceso notable).

12 Diego Jaramillo es un sacerdote eudista precursor de la RCC en Colombia junto a Rafael García Herreros. Se le reconoce como el principal líder espiritual del Movimiento en Colombia con un protagonismo social y religioso como lo es en el espacio televisivo del Minuto de Dios. Su entrevista fue fundamental para profundizar en aspectos asociados a la experiencia del Minuto de Dios 
Luego de que Ralph Keifer empezó a usar la fórmula de "Bautismo en el Espíritu" ${ }^{13}$ en ambientes metodistas, la expresión se asumió en contextos católicos para aludir a la experiencia del pentecostés personal vivido o renovado en cada bautizado (Jaramillo, 2010). Los creyentes que reciben este bautismo experimentan fenómenos como hablar en lenguas, euforia, visiones y emociones extáticas, todas ellas, experiencias sensacionales cada vez más vívidas y espectaculares (MacArthur, 1994). En el entorno católico, la experiencia del Bautismo en el Espíritu está fuera de lo sacramental, siendo una vivencia personal que se propicia en una reunión comunitaria o en privado. El Bautismo en el Espíritu como práctica distintiva del cristianismo pentecostal, lleva a una transformación de la vida o conversión (Eckolt, 2015), en la que se estimula el abandono total de lo que se considera pecaminoso, con énfasis en lo comportamental que implica en muchos casos la droga, alcohol, crímenes y un retorno a la vida sacramental (Bierman, 1973a, 1973b).

Por otro lado, este sistema de creencias implica la promoción y vivencia de los carismas ${ }^{14}$. De estos carismas se pueden identificar tanto dones extraordinarios como servicios o ministerios dentro de la comunidad que no tienen distinciones marcadas desde la dogmática. Los dones extraordinarios son el discernimiento de espíritus, profecía, don de lenguas para hablar o interpretar, sanación. Algunos de los dones de servicio o ministerios son la enseñanza, sabiduría, fe, incluso la música.

13 El bautismo en el Espíritu es una práctica propia de los movimientos pentecostales que hace referencia a la posesión del "Espíritu Santo" sobre el creyente que le genera experiencias de éxtasis con manifestaciones de los dones (glosolalia, visiones, milagros, interpretación de sueños, lágrimas, entre otros) dentro de un contexto comunitario. Las referencias son tomadas de la sagrada escritura en la teología paulina (Cf. 1 Co 12, 1-11).

14 El concepto de carisma tiene comprensiones diferentes. Desde la sociología, Weber define carisma como "cualidad que pasa por extraordinaria (...) de una personalidad, por cuya virtud se le considera en posesión a fuerzas sobrenaturales (Weber, 2012, p. 95). Desde la antropología se asocia a un factor relacional del individuo que se le atribuye a una cualidad de una persona que atraen la atención y son perceptiblemente agradables que en palabras de Clifford Geertz (1992) es "la sacralidad inherente del poder soberano". 
El uso del término carisma en la cotidianidad se hace indistintamente si es extraordinario o ministerio.

De los carismas extraordinarios, la sanación o curación de las enfermedades asociadas a lo psicológico y espiritual es uno de los dones extraordinarios de mayor relevancia dentro del entorno carismático, cuya procedencia proviene de los dones atribuidos por el Espíritu Santo. El don de curación es una capacidad de algunos creyentes y líderes carismáticos ${ }^{15}$ que se hace manifiesta por la intermediación divina, en la que, a su entender, es una acción espontánea que se manifiesta espiritual o físicamente en el beneficiario. Este carisma o don permite la propiciación de milagros que se comprenden como eventos de naturaleza extraordinaria y coincidentes con la profecía o mandamiento del líder religioso que legitima y garantiza completamente la convicción de la acción divina gracias a los testigos, certificándolo como líder comisionado por Dios (Strong en MacArthur, 1994). Esta sanación siempre se manifiesta a través del testimonio del creyente o el discernimiento de un tercero como una acción mediada por el Espíritu Santo.

De acuerdo con Csordas (1990), la curación de enfermedades físicas o emocionales por la fe se asocia con lo demoniaco, incluyéndose una variedad de imágenes multisensoriales, sentimientos y manifestaciones somáticas que indican el flujo del poder divino dentro y entre los participantes de la asamblea. En este sentido, la demonología carismática, fundamental para la RCC, considera la existencia de espíritus malignos posesivos que son causa de aquellas acciones que conducen al creyente a comportamientos

15 El líder carismático para Max Weber corresponde a uno de los tipos de liderazgo al lado del tradicional y el legal. En el caso del liderazgo carismático, se le atribuye a aquel líder que tiene legitimidad por la posesión de dones, condiciones en términos de santidad, heroísmo, carácter ejemplar o poderes superiores a los de sus seguidores (Weber, 2012). Por su parte Vallverdú (2001) considera que los líderes carismáticos son reconocidos vigías o guías del camino en la fe y la obediencia a la norma y las autoridades religiosas legitimadas. En el caso del catolicismo, es necesario saber que la distinción del líder carismático es limitada ya que algunos no son solamente carismáticos en el sentido sociológico por el poder de empatía y autoridad, sino que muchos de ellos poseen carismas espirituales, lo que los hace doblemente carismático. 
contrarios a la moral cristiana. El creyente no puede ejercer su autonomía, pues la dominación demoníaca le hace sentir al creyente que no es dueño de sí. La tarea del líder carismático consiste en propiciar su confesión en la asamblea carismática para identificar el espíritu y, con la participación del poseído, expulsar la entidad maligna de su cuerpo. Es el líder carismático quien tiene la capacidad de la sanación y del exorcismo para expulsar demonios (Bierman, 1973b; Bronx, 1990).

Las experiencias de bendición dentro de este sistema de creencias se distinguen del entorno católico tradicional por enmarcarse en una sensación extática de felicidad, paz, salud, alegría, armonía familiar, abandono de vicios, incluso abundancia económica (Csordas, 1990; ICCE, 1977; Mardones, 1994). De ahí que la creencia de bendición esté asociada directamente al testimonio. Según Ribeiro de Oliveira, la estructura del testimonio responde a una bendición y una conversión que se puede ver reflejada en la trasformación de maldición/pecado por éxtasis/conversión y bendición/salvación, haciendo parte del culto no como manifestación espontánea, sino como elemento ritual articulador del culto (ICCE, 1977).

Otro aspecto fundamental dentro de la RCC es la importancia de la biblia o Sagrada Escritura, especialmente el Nuevo Testamento por las referencias directas al Espíritu Santo. Este es el medio para acercarse de manera más personal a la experiencia cristiana, convirtiéndose en fuente de verdad. No obstante, dentro de la RCC, a diferencia de otros pentecostalismos, tiene el mismo nivel de importancia el Magisterio, aquella enseńanza legítima de la institución católica que respalda la autoridad y ortodoxia para "interpretar auténticamente la Palabra de Dios, oral o escrita” (CIC, 85) y que está bajo la responsabilidad directa de los obispos y al sucesor de Pedro, el Papa obispo de Roma.

De esta manera, se puede observar que la dogmática religiosa carismática en el catolicismo involucra significativamente la emocionalidad en una dinámica de dualidad entre pecado/salvación, sufrimiento/sanación, tristeza/alegría, cielo/infierno. Las creencias se marcan fuertemente por la interpretación literal de la biblia, la conversión como requisito para la "vida en el espíritu" y que lleva al testimonio, la muerte o renuncia como la 
representación de condición para la salvación, así como el asumir el estilo de vida de Jesús en diferencia al Diablo ${ }^{16}$ que se evoca constantemente dentro de la RCC (Cabrera, 2001). Igualmente, creen en doctrinas de la biblia y el Magisterio; enseñan y difunden la ortodoxia católica; poseen un énfasis en el Espíritu Santo a través de la vivencia de los carismas y profundizan en la experiencia de los hechos de los apóstoles, específicamente, de Pentecostés (Cabrera, 2001; Franco, 2003).

\section{Prácticas religiosas en la RCC}

Para comprender las prácticas dentro de la RCC es fundamental reconocer la función del cuerpo como la principal mediación y forma de expresión de la ritualística carismática. El ritual se centra en la dimensión corporal humana al ser el vehículo de la experiencia religiosa. Este hecho cobra relevancia en la medida en que gran parte del simbolismo ritual de la RCC se circunscribe en la expresividad y vivencia de sensaciones corporales y sobrenaturales: comida, sexualidad, dolor, paz, baile, todas formas simbólicas que se adaptan como expresión de la experiencia sagrada (Mardones, 1994). En este sentido, Csordas (1990) retoma a Mauss para afirmar que todos los humanos tienen un sentido de individualidad espiritual y corporal; a esto lo denomina (in-corpo-ración).

16 El diablo o demonio dentro de la tradición cristiana encarna a la personificación del mal que domina e incita al ser humano a realizar acciones que van en contra de la voluntad divina y humana. Este espíritu malévolo se le asocia con el poder de posesionar cuerpos, hacer hablar y comportarse contrario a la moral cristiana. Las manifestaciones son hablar en lenguas extrañas (glosolalia), cambios en la voz y en la estructura facial, ojos blancos o fuerzas extranormales y carismas como el discernimiento en forma de engaño entre otros. Otras expresiones maléficas son las misas negras, maleficios o brujerías, mal de ojo, etc. En el catolicismo, la forma de sanación es el exorcismo, especialmente de un sacerdote, pero en otros casos de laicos carismáticos y especializados en este tipo de manifestaciones. 
Desde lo social, Csordas hace una lectura a partir de la fenomenología de Merleau-Ponty, en la que ubica el cuerpo desde la relación con el mundo como un "cuerpo informado e incorporado", un principio generador y unificador de todas las prácticas y conciencia de un sistema de potencialidades objetivas (Csordas, 1990). Sin embargo, la característica de este cuerpo es que padece el dolor crónico - del pecado- que en ocasiones se transmite a otros enfermos, dado que comparten un mundo y su respectivo lenguaje en una dualidad de "mundo lleno de dolor/el dolor del mundo", convirtiéndose en pensamientos in-corporados, es decir, pensamientos que se somatizan y que comportan emociones en un mundo cotidiano de dolor constante (Greco, 2011).

Desde esta perspectiva, el creyente carismático manifiesta a través de su cuerpo el dolor crónico que proviene de la tensión pecado/salvación o cielo/infierno y que es incorporado en los pensamientos con somatizaciones como la agitación o vibración rápida de las manos y los brazos, sensaciones de ligereza o pesadez, el poder o el amor que fluyen por el cuerpo, el calor y el hormigueo. Otras manifestaciones son la risa espontánea o las lágrimas pueden propagarse de manera contagiosa en oleadas emotivas a través de la congregación (Csordas, 1990; Greco, 2011; Ospina Martínez, 2004). De ahí que la animosidad extática mediada por el cuerpo haga parte fundamental del culto carismático debido a su incidencia en las prácticas como ejercitación de los dones, especialmente el de curación y lenguas. Estas prácticas se pueden ubicar en un nivel organizacional macro (asamblea) y micro (grupo de oración).

En el primer nivel, la asamblea es una de las prácticas comunes en el RCC para la oración y enseńanza masiva en el que se produce y reproduce un mundo simbólico para la vivencia religiosa personal e intensa. La asamblea se convierte en el espacio y forma de culto en el que los creyentes expresan de forma libre y comunitaria su oración, reciben la enseñanza por parte del líder carismático, vivencian experiencias extáticas con los cantos religiosos, la oración de sanación y la adoración (O’Connor, 1973). Allí se exhorta y se es exhortado como una forma de reafirmar la validez de este mundo carismático de manera colectiva. Esta asamblea tiene la característica de ser la mayor expresión de la alegría y congregación, que se convierte en señal de bendición/salvación como posibilidad para ejercitarse en los "dones" de la 
curación, la glosolalia y la profecía (ICCE, 1977) como se pudo evidenciar en las experiencias carismáticas contemporáneas observadas en el trabajo de campo de la investigación.

La asamblea es el espacio donde los creyentes participan activamente de forma emotiva no especializada a través de los testimonios donde se reafirma el carisma, la constitución de la comunidad y la doctrina de la fe. A diferencia del culto tradicional católico donde el protagonista es el sacerdote, líder especializado en la doctrina cuya legitimidad le permite proferir los discursos y oraciones en un ritual, en la asamblea carismática el líder (laico o sacerdote) es un regulador de las expresiones. Los participantes esperan del mensaje carismático para que la sanación ocurra a lo largo de las sesiones o durante los momentos discretos cuando los ministros están orando sobre ellos con la imposición de manos.

Los ritos de la asamblea se conciben como formas de la comunicación que expresan la adoración, el perdón o cualquier otro tipo de súplica. Según Csordas (1990), la diferencia entre una reunión para propósitos de adoración y una para la experiencia del poder divino está determinada por el énfasis de carismas que establecen los líderes y su propio equipo de experimentados ministros. En este sentido, las alabanzas se caracterizan por la utilización de música muy animada, que difiere del tipo de comunidad si es más asociada a ritmos modernos y bailables o más tradicionales. No obstante, la emotividad común a la experiencia carismática es llamativa por su influencia en motivar y congregar mayor afluencia de adeptos, especialmente niños y adolescentes.

La enseñanza en la asamblea es aquella comunicación religiosa referente al culto, creencias, prácticas y temáticas de la institución (Luhmann, 2007). En la RCC, la enseñanza es un espacio discursivo que se direcciona a través de conferencias por especialistas religiosos, en ocasiones cursos y para el caso particular, los Seminarios de vida en el espíritu o Seminarios de Renovación espiritual, que son experiencias de evangelización en las que se le conduce al creyente por un proceso de conocimiento y conversión a partir del Bautismo del espíritu, pasando por el conocimiento de la divinidad hasta el compromiso como cristiano en la Iglesia como lo sostuvo en entrevista el padre Diego Jaramillo (2017) del Minuto de Dios. 
En el nivel micro, los grupos de oración son otra práctica característica de la RCC. Este espacio de interacción se empieza a implementar cuando el crecimiento del número de los fieles o el tamaño del territorio obliga a los ministerios más grandes a buscar un punto intermedio entre la evangelización a gran escala y la necesidad de integrar activamente a los miembros en la estructura organizativa. Estos espacios de interacción y de pertenencia posibilitan prácticas como la lectura de la biblia, la oración colectiva (a veces muy emocional), las enseñanzas propias de las asambleas o la literatura especializada en un contexto de emotividad propiciada por las sensaciones sobrenaturales de alegría y paz (Bierman, 1973a, 1973b; Cabrera, 2001; Greco, 2011; O’Connor, 1973).

La importancia de los testimonios de conversos o sanados son parte fundamental del rito que se expresan a modo de exhortación para la conversión de los "hermanos" donde se relatan experiencias negativas y de frustración de cada uno de los conversos que terminan con la descripción de su encuentro con Cristo y la Renovación del espíritu, manifestada a través de un éxtasis, expresión de alguno de los dones del Espíritu Santo (ICCE, 1977). Estos testimonios se convierten en lamentos rituales dentro del culto carismático, más que manifestaciones espontáneas de los creyentes. Sin embargo, su función exhortativa tiene la fuerza de provocar efectos emocionales en la asamblea o el grupo de oración, llevando a exclamaciones propias de la expresión pentecostal o carismática como "Amén” "Aleluya" "alabado sea Dios" “ßBendito sea el nombre del Señor!" no solo durante alguna intervención oratoria, sino durante todo el culto (ICCE, 1977, p. 170).

Por otro lado, una práctica frecuente en los grupos de oración es la glosolalia ${ }^{17}$, un lenguaje incorporado en el creyente cuyo significado religioso se asocia a "la palabra divina encarnada", la unidad de lo humano y lo divino

17 La glosolalia o el don de lenguas se define como una capacidad espontánea de balbucear o de hablar en una lengua desconocida que generalmente es interpretada por otro creyente que tiene el don del discernimiento. Esta experiencia se presenta normalmente en la asamblea o grupo de oración de una comunidad carismática. La glosolalia es propia del cristianismo pentecostal (Ornelas, 2018). 
que es interpretado por otro miembro al ser una comunicación para la comunidad. Los carismáticos típicamente describen las lenguas como una experiencia extática que excita el espíritu de forma que se expresa en un lenguaje particular (MacArthur, 1994). De acuerdo con Csordas (1990), la glosolalia carece de linealidad en la expresión semántica porque resalta el significado gestual del lenguaje más que el significado del mensaje siendo un acto puro de expresión. Cada una de estas posiciones aporta a la comprensión del fenómeno, dejando un significado cultural de la glosolalia como una forma de expresión que es y no es lenguaje. De ahí que la glosolalia se pueda comprender como "distintas formas de comunicar significados religiosos dependientes de contextos rituales particulares" (Ornelas, 2018, p. 97).

\section{Identidades carismáticas en el interior de la RCC y el catolicismo}

La identidad se puede considerar como una emergencia simultánea entre la identidad del creyente desde su subjetividad y la identidad como propiedad de la organización religiosa, la cual tiene la capacidad de atribuir sentido a su feligresía y emerge directamente en la dinámica de autoorganización del sistema, convirtiéndose en dispositivo para la habituación de los sujetos. En este sentido, la identidad se debe comprender con relación a la cultura y la conformación de un estilo de vida que es vivido y experimentado por los sujetos humanos (Luhmann, 2007; Ornelas, 2015).

Para el caso del catolicismo, y siguiendo los estudios de la investigadora social De la Torre $(2001,2006,2018)$ en torno a las identidades religiosas en la RCC, la observación nos conduce a reconocer que la Iglesia católica como sistema religioso está conformada por subsistemas organizacionales (NMR) -como la RCC- que a su vez incluye otros subsistemas (corporaciones carismáticas, asociaciones de fieles, movimientos eclesiales). Es en este nivel micro donde se puede rastrear que la concepción de identidad "católico" está sujeta a dinámicas de afinidad y tensión en una paradoja de organización horizontal/vertical entre los líderes de las organizaciones religiosas y los miembros de la Iglesia católica. Los procesos de diferenciación entre la lógica institucional que busca la unidad y la diversidad de lógicas expresadas en 
las identidades de los creyentes católicos en los NMR se proyectan como una dinámica dada en el interior de la RCC.

La RCC dentro del catolicismo durante los 70's se complejizó debido a la pluralización religiosa en el interior de la tradición religiosa con adaptaciones innovadoras del mundo secular en su autoorganización. La apuesta por una religión más cercana a las demandas de sus creyentes sin infringir el Magisterio y respondiendo a "los signos de los tiempos" del mundo secular, fue una decisión no reconocida por la generalidad institucional en este período, lo que confluyó en la constitución de pequeñas organizaciones abiertas y cerradas con respecto a la RCC.

Desde el interés investigativo, la identidad de estos grupos religiosos (llámese grupo de oración, asamblea, comunidad, movimiento que muchas veces tienen reconocimiento jurídico reconociéndose como corporaciones, asociaciones, institutos) cobra relevancia al ser dispositivos que permiten fortalecer los vínculos entre la membresía y la organización religiosa a través de la regularización de la vida cotidiana que ordena las prácticas individuales de sus miembros a través de las constantes comunicaciones dadas en la vivencia litúrgica o en el quehacer diario a través de los medios de comunicación. En este sentido, la identidad religiosa está ligada fuertemente a las creencias, la fe, las ideas, los valores, los sentimientos de base religiosa, decisivo en los procesos de construcción de identidad y distinción con otros sectores y grupos sociales que se encuentran en la sociedad urbana (Barrera Lara, 2005).

La identidad del creyente carismático como estilo de vida implica un nuevo espíritu emocional cuyo gusto por la interacción en grupos, por la participación colectiva en las asambleas, la experiencia de carismas extraordinarios así como el compromiso de servicio y expresividad espiritual con otras comunidades en el interior y exterior de sus agrupaciones, conduce a que sus miembros refuercen sus redes sociales a través de la experiencia religiosa que viven dentro de las Comunidades Renovadas (Barrera Lara, 2005; Vallverdú, 2001, 2003). Ante este fenómeno, los autores sostienen que el énfasis de las nuevas organizaciones prioriza las opciones individuales disponibles con demandas asociativas o institucionales de compromiso más o menos 
estrictas. Por ello, se comprende que los medios de comunicación (radio, televisión, redes sociales) sean la alternativa para que los modelos religiosos o espirituales establezcan los diferentes márgenes de flexibilidad en el ámbito ideológico, normativo y práctico, al tiempo que establecen límites de la organización en la medida que dibujan diversos perfiles de conversión o adhesión que influyen en la construcción de identidades colectivas de diferente índole (Eckolt, 2015; Vallverdú, 2001).

En el caso colombiano, la producción de material y la incursión en los medios de comunicación contribuyó al conocimiento de las dinámicas del movimiento en todo el país, propiciando espacios de comunicación (retiros, encuentros, congresos, seminarios) en los que se ponían en circulación las comunicaciones materiales (folletos, libros, cassetes de música) que usaban en los encuentros locales y regionales como lo sostuvieron los entrevistados Weigand, Jaramillo y Toro ${ }^{18}$. Por otro lado, a nivel de subsistemas de la RCC, se observa la emergencia de comunidades como unidades autónomas que en línea carismática católica se organizaban con la forma de corporación carismática, asociación de fieles o de laicos, e incluso como instituto laical. Sus funciones asociadas a los carismas o ministerios fueron la de contribuir a la oferta religiosa especializada en los procesos de trabajo pastoral adelantados por la institución eclesial. En Colombia son destacadas las comunidades constituidas a partir del liderazgo del Minuto de Dios (Jaramillo, 2016, 2017) la parroquia San Juan Bautista, específicamente en parte del centro y sur del país (Toro, 2018; Weigand, 2018) y emprendimientos religiosos de laicos de diferentes comunidades católicas y no católicas (Espinosa, 2004; Toro, 2018).

La emergencia de estas comunidades o grupos son relevantes en la perspectiva de identidades católicas ya que sus énfasis en los carismas connotaban una especialización funcional que incidía en los intereses de participación de la feligresía. En este sentido, la participación laical estuvo

18 Germán Toro fue uno de los precursores y participante activo de la RCC en Cali. Su liderazgo contribuyó a la consolidación del movimiento al lado del Padre Guillermo Weigand. Posteriormente viajó a Estados Unidos donde desarrollo su ministerio diaconal. En la actualidad es un líder activo dentro de la Iglesia Católica en Estados Unidos y varias ciudades de Colombia. 
correlacionada directamente con la especialización del grupo carismático. En general, se pueden observar identidades asociadas al tipo de carisma (enfoques en la Virgen María, sanación, don de lenguas, profecía), también al tipo de población (enfoques en los niños, los matrimonios, los jóvenes, las mujeres) e incluso al tipo de clase social (enfoques en comunidades de estratos bajos, medios y altos), lo que contribuyó en los procesos de habituación de sus creyentes y, por tanto, en la configuración de estilos de vida carismáticos católicos. Si bien algunas comunidades fueron afiliadas directas al Minuto de Dios como corporación, se reconocen rupturas con la conformación de asociaciones e institutos autónomos, desligados de la RCC e incluso de las parroquias.

\section{Las comunidades eclesiales en Colombia: diversidad de identidades carismáticas}

Dentro del catolicismo, las identidades de los creyentes carismáticos se pueden rastrear en las dinámicas organizacionales y la especialización carismática de las corporaciones, asociaciones de fieles, movimientos eclesiales que constituyeron sus propios sistemas de prácticas y creencias. En el caso colombiano, este campo se ha desregulado y pluralizado con una amplia oferta de comunidades carismáticas que ofrecen alternativas de espiritualidad y vivencia religiosa particular según las demandas de los creyentes. Si bien se pueden identificar distinciones en un período temporal específico, es fundamental reconocer que estos procesos se han transformado en el transcurrir del tiempo con adaptaciones cada vez más cercanas al mundo secular.

Algunos ejemplos según el tipo de comunidades laicales en Colombia son las asociadas al Minuto de Dios (como la comunidad Pueblo de Dios, fundada el 26 de Julio de 1972 por Ana de Laguna, su dirigente y quien después de su conversión en un Eccla ${ }^{19}$ trabajó articulada al Minuto de

19 El Encuentro Católico Carismático Latinoamericano ECCLA es un espacio a nivel latinoamericano donde se reúnen los líderes religiosos de la RCC para discutir, revisar 
Dios) y la RCC, en función de la formación y el trabajo pastoral con adultas mayores, desprotegidas y abandonadas. Otra agrupación es la Comunidad Alegría nacida en el seno del Minuto de Dios como una comunidad matrimonial en mayo de 1985. Su misión se materializa en la evangelización de la familia al estilo de la RCC provenientes de diferentes comunidades y grupos de oración en varias diócesis y comunidades matrimoniales de América Latina (Téllez Villamil, Quintero González, $\&$ Prieto Izquierdo, 2016).

Por otro lado está la Asociación María santificadora (1979), cuyo origen parte de un grupo ecuménico en 1970 liderado por Nelly de Rodríguez de las Misiones de Estados Unidos pero que se formaliza por influencia del movimiento carismático de Ecuador donde participó la fundadora Gloria Niño de Gómez. Igualmente se destaca Esther Julia Garzón, quien se convirtiera de las Asambleas de Dios a la Iglesia católica desde 1971 y desarrolló sus labores de evangelización y coordinación de la obra de Carisma en Misiones en Medellín entre los años 1972 y 1976. En los 90, se conoce la asociación laica Lazos de Amor Mariano (LAM), fundada por el laico José Rodrigo Jaramillo Fernández el 16 de Julio, día de la Virgen del Carmen, en el año 1999, en la Ciudad de Medellín, Colombia. En este grupo se destaca su trabajo especializado con niños, jóvenes, noviazgos y matrimonios especialmente de clases medias y bajas articulados con las parroquias. De las asociaciones de María santificadora y Lazos de Amor Mariana se resalta no sólo su especialización en la Virgen María, sino también su negación de autorreferenciación como grupo carismático o en relación a la espiritualidad carismática de la RCC.

A nivel de religiosos y sacerdotes es reconocida la asociación sacerdotal Seminario Misionero del Espíritu Santo fundada por Monseñor Uribe Jaramillo el 4 de septiembre de 1980. El interés de esta iniciativa formativa fue la especialización carismática de los sacerdotes con una formación enfocada en la vivencia de los carismas, realizando seminarios de vida nueva, grupos de oración, pastoral con la RCC. Por otro lado, se pensó

y regular aspectos de la Renovación Carismática Católica en la región. Se considera como el primer ECCLA en 1973 en la ciudad de Bogotá Colombia. Periódicamente se continúan realizando los encuentros en diferentes partes de la región (Jaramillo, 2016). 
como la asociación sacerdotal en el país que direccionaría el movimiento de la RCC a nivel nacional. Sin embargo, tal diferenciación no se consiguió por la creciente especialización en lo carismático de los sacerdotes del clero secular, las comunidades religiosas y el impulso en las parroquias de la liturgia carismática al lado de diferencias y resistencias por parte de algunos de sus miembros que no asumieron este tipo de espiritualidad en el interior de la organización como lo sostuvo en entrevista el padre Abelardo Giraldo ${ }^{20}$.

Con ello se puede evidenciar que las asociaciones o corporaciones que emergieron dentro de la organización RCC no solo fueron respuesta a las demandas de los creyentes, sino que se constituyeron en alternativas de participación laical con acompañamiento y seguimiento a nivel presencial por los líderes carismáticos y la vinculación en los eventos rituales, así como por la comunicación a través de diferentes medios. Estas experiencias y comunicaciones, especializadas en muchos casos, implicaban la ampliación en todas las esferas sociales de los creyentes con subjetivación constante en la casa, el trabajo a través de la radio. En este sentido, la música, los programas familiares y todas las propuestas mediáticas se convirtieron en la estrategia para incorporar nuevas prácticas y excluir aquellos comportamientos que diferían del sistema simbólico religioso de la RCC.

Por tanto, la identidad religiosa de RCC se comprende como una diversidad interna dentro del catolicismo que se adapta al mundo secular con identidades hibridas y que corresponde a la especialización carismática que al ser difusa se hace denominar "espiritualidades" en el interior del catolicismo. No obstante, dentro de los procesos de diferenciación organizacional, la conversión como requerimiento para refundar la identidad carismática se convierte en la manera en que se inicia al creyente para una vinculación que lo reafirma en la Iglesia católica, la vivencia carismática y la especialización

20 El sacerdote Giraldo exmiembro del seminario del Espíritu Santo considera que la pluralización de vivencias en el interior del mismo seminario, la resistencia por algunos de vivir exclusivamente la experiencia carismática dentro del seminario, y el influjo que tienen los sacerdotes eudistas del Minuto de Dios no permitió que se cumpliera con el objetivo de que este instituto sacerdotal fuera el dinamizador de la RCC en Colombia. El seminario sigue funcionando, pero sin estar exclusivamente enfocado en lo carismático (Entrevista a Giraldo, 2016). 
ministerial de acuerdo con la comunidad a la que pertenece. El sentido profundamente emocional y transformador es el vínculo interpersonal que alinea el comportamiento religioso a la ideología comunitaria. Desde esta perspectiva, la visión de familiaridad y amistad son derroteros para fortalecer la membresía de estas comunidades emocionales que en un entorno de competencia les obliga a establecer estrategias de fidelización y regulación para vigorizar la organización y garantizar los procesos de habituación de sus creyentes en estilos de vida carismáticos.

\section{Conclusiones}

La yuxtaposición o hibridez de creencias y prácticas entre el catolicismo tradicional y el pentecostalismo, producto de las adaptaciones e intercambios entre creyentes pentecostales y católicos, se caracteriza por experiencias religiosas carismáticas, con mayor emocionalidad, cercanía a psicoterapias y procesos de sanación, además de una espontaneidad colectiva e individual en los procesos de conversión y su influencia directa en actitudes y decisiones religiosas sobre los éxitos personales, familiares, profesionales y sociales (Eckolt, 2015). Estas formas híbridas evolucionaron en su sentido transitando de un primer momento en lo social hacia lo religioso y emocional con la configuración de nuevas formas de expresión religiosa que se terminaron constituyendo en organizaciones religiosas o NMR en el interior del catolicismo y que según algunos autores se denominó como un fenómeno de pentecostalización de la Iglesia Católica (Bastian, 1994, 1997; De Roux, 2017; Eckolt, 2015).

La RCC como movimiento religioso se enfocó más en el don del Espíritu Santo, hablar en lenguas y practicar la sanación por el Espíritu en un giro comunitarista-intimista de los nuevos movimientos cristianos (Faggioli, 2011). Esta adaptación no solo comenzó a dar respuesta al incremento de sectas protestantes en el país, sino que permitió reavivar el culto católico y activar la membresía católica que venía distanciándose de la práctica religiosa. Siguiendo a la historiadora Moreno (2011), las formas de religiosidad pentecostal dentro del catolicismo reivindicaron la emoción 
y la oralidad como un aspecto relevante de la experiencia religiosa y por tanto, permitió la estabilidad del sistema religioso en su membresía y una recomposición de la cultura religiosa, es decir, "una reconstrucción de las representaciones religiosas tanto en el contenido como en la forma” (p. 42).

Esta etapa de consolidación que tuvo su auge en los años 70 luego tuvo inconvenientes con parroquias y grupos como resultado de desacuerdos con la jerarquía católica (Barrera Lara, 2005) y por la pluralización que se comenzó a dar en línea carismática con otros movimientos eclesiales en el interior del catolicismo (Soneira, 2007). Sin embargo, muchas de las comunidades que nacieron en este seno han desaparecido o se han fusionado con otros grupos, perdiendo identidad y al mismo tiempo fuerza. De ahí que la RCC pueda ser objeto de dos lecturas que se complementan. La primera que el movimiento ha decrecido por la falta de atención, difusión y por la falta de participación de los sacerdotes, ya que no todos acogen este movimiento con entusiasmo; algunos solo lo toleran y se ha perdido el entusiasmo que en parte es la postura del líder Diego Jaramillo (2017). La segunda postura es que la complejización del entorno carismático entendida como pluralización de grupos y especializaciones carismáticas ha llevado que la RCC sea percibida como un movimiento difuso más que una organización, una forma de iglesia en movimiento que incorporó creencias y prácticas en el culto cotidiano de las parroquias como lo afirmó el líder Germán Toro (2018) en la entrevista.

No obstante, la realidad es que el ser creyente carismático como un estilo de vida ha tomado fuerza con formas innovadoras de rituales (retiros, encuentros especializados, conferencias), de estilos propios de los carismáticos con fuertes influencias de los medios de comunicación (redes sociales, televisión, radio), todas características de una nueva forma de vivenciar el catolicismo actualmente y que no solo son patentadas por las organizaciones especializadas en lo carismático, sino que son asumidas en el rito parroquial cotidiano donde tiene lugar la vivencia de una pluralidad de espiritualidades católicas que se entrecruzan entre las prácticas religiosas en lo ritual e institucional del catolicismo con otras prácticas y discursos propias del mundo secular o de otros sistemas religiosos no cristianos. 


\section{Referencias}

Alberigo, G. (2005). Breve historia del Concilio vaticano II: 1959-1965. Salamanca, Espańa: Sígueme

Arias, R. (2003). El episcopado colombiano. Intransigencia y laicidad (1850-2000). Bogotá, Colombia: ICAHN, Uniandes

Barrera Lara, I. (2005). El Movimiento de Renovación Carismática en el sector rural y urbano del centro de Veracruz: interacción social, impacto social e identidad. Cuicuilco, 12(34), 201-215. Recuperado de http://www.redalyc. org/html/351/35103409/

Bastian, J. P. (1994). Protestantismo y modernidad latinoamericana. Historia de unas minorias religiosas activas en América Latina. México D.F., México: Fondo de Cultura Económica

Bastian, J-P. (1997). La mutación religiosa en América Latina. México D.F., México: Fondo de Cultura Económica

Bergunder, M. (2009). Movimiento pentecostal en América Latina: Teorías sociológicas y debates teológicos. Revista Cultura y Religión, 3(1), 6-36 Recuperado de https://dialnet.unirioja.es/servlet/articulo?codigo=2952572

Bierman, E. (1973a). El movimiento pentecostal. Revista Javeriana, 79(392), 158-164.

Bierman, E. (1973b). El movimiento pentecostal católico. Revista Javeriana, 80(396), 449-468.

Bronx, H. (1990). El obispo Alfonso Uribe Jaramillo. Biblioteca Benigno A. Gutierrez. Medellín, Colombia: Litoplex.

Cabrera, P. (2001). Nuevas prácticas. Nuevas percepciones. La experiencia de la Renovación Carismática Católica. Ilha Revista de Antropologia, 3(1), 121-137. https://doi.org/10.5007/\%X

Carranza, B. (2005). Movimientos do Catolicismo Brasileiro: Cultura, Midia, instituição. Universidade Estadual de Campinas. Recuperado de https:// www.academia.edu/11170376/Dávila_Brenda_Maribel_Carranza_1_

Carranza, B. (2008). 40 años de RCC: un balance societario. Ciencias Sociales y Religión/Ciências Sociais e Religiāo, 10(10), 85-116. https://doi. org/10.22456/1982-2650.6915 
Carranza, B. (2011). Catolicismo Mediático. (1ª ed.). Aparecida,Brasil: Editora Idéias \& Letras

CIC. (s. f.). Catecismo de la Iglesia Católica. Recuperado 9 de agosto de 2018, de http://www.vatican.va/archive/catechism_sp/p1s1c2a2_sp.html

Csordas, T. J. (1990). Embodiment as a Paradigm for Anthropology. Ethos, 18(1), 5-47. https://doi.org/10.1525/eth.1990.18.1.02a00010

De la Torre, R. (2001). Religiosidad popular. Anclajes locales de los imaginarios globales. Siglo XXI Continuidades y Rupturas, 5, 98-117

De la Torre, R. (2006). La Ecclesia nostra : el catolicismo desde la perspectiva de los laicos : el caso de Guadalajara. México D.F.: Fondo de Cultura Económica.

De la Torre, R. (2007). La Diversidad Católica Vista desde los Nuevos Rostros de Dios. Ciencias Sociales y Religión/Ciências Sociais e Religião, 5(5), 11-36. https://doi.org/10.22456/1982-2650.2252

De la Torre, R. (2018). Videogracia y las Recomposiciones de la Religiosidad Contemporánea en Latinoamérica. Forum for Inter-American Research FIAR, 11(1), 19-33. Recuperado de http://interamerica.de/volume-11-1/ de-la-torre/

De Roux, R. (2017). La Iglesia católica en América Latina a la hora del papa Francisco. Caravelle, (108), 35-49. https://doi.org/10.4000/caravelle.2244

Echeverry Pérez, A. (2007). Teología de la liberación en Colombia: un problema de continuidades en la tradición evangélica de opción por los pobres. Cali, Colombia: Programa Editorial, Universidad del Valle

Eckolt, M. (2015). El fenómeno de los Nuevos Movimientos Religiosos: una lectura desde Latinoamérica. Medellín. Biblia, Teología y Pastoral para América Latina y El Caribe, 39(154), 195-214. Recuperado de http://documental.celam. org/medellin/index.php/medellin/article/view/39

Espinosa, G. (2004). The Pentecostalization of Latin American and US Latino Christianity. Pneuma, 26(2), 262-292. Recuperado de http://www.academia. edu/download/36650479/Espinoza_Gaston_-_The_Pentecostalization_ of_Latin_America_and_U.S._Latino_Christianity.pdf

Fernández, P. (1978). La renovacion carismatica : documentación pontificia, episcopal y teológica. Salamanca: Ediciones Secretariado Trinitario

Franco, F. (2003). Cuerpo y “misticismo” en las Misas de Sanación del Movimiento de Renovación Carismática Católico en Mérida (Venezuela). LiminaR, 8(2), 
71-88. Recuperado de http://www.scielo.org.mx/scielo.php?pid=S1665$80272010000200005 \&$ script=sci_arttext $\&$ tlng=pt

Frigerio, A. (1998). Desregulación del mercado religioso y expansión de nuevas religiones: una interpretación desde la oferta. En XXII Encontro Anual da ANPOCS (pp. 27-31). Brasil: Caxambu, MG

Geertz, C. (1992). Centros, reyes y carisma: Una reflexión sobre el simbolismo del poder. Ensayos sobre la interpretación de las culturas. En Conocimiento local (pp. 147-171). Buenos Aires, Argentina: Paidós

Giménez Béliveau, V. (2008). Sociabilidades, liderazgos e identidad en los grupos católicos argentinos. Un acercamiento al fenómeno de los comunitarismos a través del caso de los seminarios de formación teológica. En A. Alonso (Ed.), América Latina y el Caribe: territorios religiosos y desafíos para el diálogo (1a ed, pp. 141-162). Buenos Aires: Consejo Latinoamericano de Ciencias Sociales - CLACSO. Recuperado de http://biblioteca.clacso.edu.ar/clacso/ $\mathrm{gt} / 20150115051526 /$ territorios_religiosos.pdf\#page $=139$

Grasso, D. (1984). Los carismas en la Iglesia : teologia e historia. Madrid, España: Ediciones Cristiandad

Greco, M. (2011). Pensamientos encarna-dos y emociones corpo-rizadas: impresiones sobre una entrevista cualitativa en profundidad a dos vecinos de un excentro clandestino. En Seminario Alquimias etnográficas : subjetividad y sensibilidad teórica (p. 19). Buenos Aires. Recuperado de http://www. antropologiadelasubjetividad.com/images/trabajos/mauro_greco.pdf

Holland, C. (2011). Historia y desarrollo del Movimiento de Renovación Carismática en América Central. Recuperado de http://www.prolades.com/cra/regions/ cam/mrc_historia_cam.pdf

ICCE. (1977). Renovación en el espíritu: movimientos carismáticos en América Latina. Bogotá: Secretariado General CELAM.

Irarrázaval, D. (2000). Procesos religiosos y reelaboración teológica. Teología y vida, 41(2), 145-163. https://doi.org/10.4067/S0049-34492000000200002

Jaramillo, D. (2010). Historia de la Renovación Carismática Católica (5ta ed.). Bogotá, Colombia: Corporación Centro Carismático Minuto de Dios.

Jaramillo, D. (2016). Latinoamérica Carismática. Bogotá, Colombia: Corporación Centro Carismático Minuto de Dios.

Luhmann, N. (2007). La religión de la sociedad. (A. Kieserling, Ed., L. Elizaincín, Trad.) (1a ed.). Madrid, España: Editorial Trotta. 
MacArthur, J. (1994). Diferencias doctrinales entre los carismáticos y no carismáticos. El Paso, EE.UU.: Casa Bautista de Publicaciones.

Mardones, J. M. (1994). Para comprender las nuevas formas de la religión : la reconfiguración postcristiana de la religión. Verbo Divino.

Moreno, C. (2011). Discursos y estrategias de la Iglesia Católica frente a la pluralización religiosa en Colombia. Revista Guillermo de Ockham, 9(2), 41-51 https://doi.org/10.21500/22563202.579

O’Connor, E. D. (1973). La renovación carismática en la Iglesia Católica. (Traducido por Mario B. Cantolla, Ed.) (4ta ed.). México D.F., México: Lasser Press.

Oliveros Maqueo, R. (1990). Historia Breve de la Teología de la Liberación (1962-1990). En I. Ellacuría \& J. Sobrino (Eds.), Mysterium liberationis: conceptos fundamentales de la teología de la liberación. (I, pp. 17-50). Madrid: Trotta. Recuperado de https://www.ensayistas.org/critica/ liberacion/varios/oliveros.htm

Ornelas, M. (2015). Niklas Luhmann: “Sociología de la religión”. Revista Mad, 32, 149-155. Recuperado de https://revistamad.uchile.cl/index.php/RMAD/ article/download/36568/38177/0

Ornelas, M. (2018). El don de lenguas como Kriya: La conexión hinduista. Revista Religión y Cultura, 12(1), 97-114. Recuperado de https://www. researchgate.net/profile/Marco_Ornelas2/publication/326158445_ EL_DON_DE_LENGUAS_COMO_KRIYA_LA_CONEXION_ HINDUISTA_Speaking-in-Tongues_as_Kriya_The_Hindu_Connection/ links/5b3ba8e0a6fdcc8506eeae39/EL-DON-DE-LENGUAS-COMOKRIYA-LA-CONEXION-HINDUIST

Ospina Martínez, M. A. (2004). Apuntes para el estudio antropológico de la alabanza carismática católica. Convergencia. Revista de Ciencias Sociales (Vol. 11). Universidad Autónoma del Estado de México. Recuperado de https://www. redalyc.org/articulo.oa?id=10503602

Ospina Martínez, M. A. (2006). En busca del ágape: Un estudio etnográfico de la Renovación Carismática Católica en Colombia. En Poder y carisma : dos aproximaciones al panorama religioso urbano (p. 248). Bogotá, Colombia: Universidad Nacional de Colombia, Sede Bogotá.

Ospina Martínez, M. A. (2006). Satanás se desregula: sobre la paradoja del fundamentalismo moderno en la Renovación Carismática Católica. Universitas Humanistica, 61, 135-162. Recuperado de https://revistas. javeriana.edu.co/index.php/univhumanistica/article/view/2083 
Ospina Martínez, M. A. (2007). La Renovación Carismática Católica: una fuente contemporánea de la eterna juventud. En F. S. y W. B. Clemencia Tejeiro (Ed.). En Creer y poder hoy: Memorias de la Cátedra Manuel Ancizar de la Universidad Nacional de Colombia (pp. 389-409). Bogotá, Colombia.

Salazar Palacio, H. (1996). La guerra secreta del cardenal López Trujillo (1ed ed.). Temas de Hoy.

Soneira, A. J. (1996). Los Movimientos Eclesiales y la Iglesia en la Argentina: el caso de la Renovación Carismática. Recuperado de http:/www.prolades.com/ documents/charismatics/4-Soneira.PDF

Soneira, A. J. (2000). La renovación carismática católica en la Argentina: ¿Religiosidad popular, comunidad emocional o nuevo movimiento religioso? Scripta Ethnologica, XXII. Recuperado de http://www.redalyc.org/pdf/148/ Resumenes/Resumen_14802207_1.pdf

Soneira, A. J. (2005). Catolicismo, estrategia institucional y democracia. El caso de los Movimientos Eclesiales. En VII Congreso Nacional de Ciencia Política. Sociedad Argentina de Análisis Político SAAP

Soneira, A. J. (2007). Catolicismo, movimientos eclesiales y globalización en Latinoamérica. Revista Cultura y Religión, 1(1), 6. Recuperado de https:// dialnet.unirioja.es/servlet/articulo?codigo $=2785590$

Stoll, D. (1985). ¿Pescadores de hombres o fundadores de Imperio? Quito: Instituto Lingüístico de Verano en América Latina.

Suárez, A. L. (2014). Nuevos movimientos y comunidades eclesiales "católicas”¿Qué renuevan? Sociedad y religión, 24(42), 92-131. Recuperado de http://www.scielo.org.ar/scielo.php?script=sci_arttext\&pi $\mathrm{d}=$ S1853-70812014000200005

Téllez Villamil, R. N., Quintero González, C., \& Prieto Izquierdo, F. (2016). Fundación Comunidad Matrimonial Alegría Pastoral Familiar Carismática Minuto de Dios. Medellín: teología y pastoral para América Latina, 41(161), 123-135. Recuperado de http://documental.celam.org/medellin/index.php/ medellin/article/view/104/105

Vallverdú, J. (2001). Mercado religioso y movimientos carismáticos en la modernidad. Gazeta de Antropología, 17(22). Recuperado de http://www. gazeta-antropologia.es/?p=3282

Vallverdú, J. (2003). Movimientos carismáticos e identidades religiosas. En C. V. Zambrano (Ed.), Confesionalidad y politica : confrontaciones multiculturales por el monopolio religioso, 2003, ISBN 958-701-333-6, págs. 213-228 (pp. 
Estilo de vida carismático en el catolicismo: proximidades sociológicas a las creencias

y prácticas de la renovación carismática católica

213-228). Universidad Nacional de Colombia. Recuperado de https:// dialnet.unirioja.es/servlet/articulo?codigo $=2306063$

Viotti, N. (2011). La literatura sobre las nuevas religiosidades en las clases medias urbanas. Una mirada desde Argentina. Revista Cultura y Religión, 5(1), 4-17. Recuperado de http://www.academia.edu/997994/La_literatura_sobre_las_ nuevas_religiosidades_en_las_clases_medias_urbanas._Una_mirada_desde_

Weber, M. (2012). Economía y sociedad. Esbozo de sociología comprensiva. (J. M. Echavarría, Trad.). México D.F., México: Fondo de Cultura Económica.

\section{Entrevistas}

Giraldo, A. (2016). Entrevista semiestructurada 1 de Agosto. Entrevistador John Urrego.

Jaramillo, D. (2017). Entrevista semiestructurada 8 de Febrero. Entrevistador John Urrego.

Toro, G. (2018). Entrevista semiestructurada 14 de Abril. Entrevistador John Urrego.

Weigand, W. (2018). Entrevista semiestructurada 23 de Mayo. Entrevistador John Urrego. Bogotá, Colombia. 